IRA-International Journal of Management \&

Social Sciences

ISSN 2455-2267; Vol.17, Issue O2 (Q.2 2021)

Pg. no. 37-45.

IRA Academico Research

\title{
Research on Rural Leisure Planning and Design from the Perspective of Rural Revitalization
}

\author{
Yu Xiaohui ${ }^{1 \#} \&$ Zhao Hui ${ }^{2}$ \\ ${ }^{1,2}$ China Architectural Design \& Research Institute Co., Ltd. China.
}

${ }^{\text {\# }}$ corresponding author

Type of Work: Peer Reviewed.

DOI: https://dx.doi.org/10.21013/jmss.v17.n2.p3

How to cite this paper:

Xiaohui, Y., Hui, Z. (2021). Research on Rural Leisure Planning and Design from the Perspective of Rural Revitalization. IRA-International Journal of Management \& Social Sciences (ISSN 2455-2267), 17(2), 37-45. DOl: https://dx.doi.org/10.21013/jmss.v17.n2.p3

(C) IRA Academico Research.

(c) Br-No $_{\text {B }}$ This work is licensed under a Creative Commons Attribution-NonCommercial 4.o International License subject to a proper citation to the publication source of the work.

Disclaimer: The scholarly papers as reviewed and published by IRA Academico Research are the views and opinions of their respective authors and are not the views or opinions of IRA Academico Research. IRA Academico Research disclaims any harm or loss caused due to the published content to any party.

IRA Academico Research is an institutional publisher member of Publishers International Linking Association Inc. (PILA-CrossRef), USA. IRA Academico Research is an institutional signatory to the Budapest Open Access Initiative. Hungary advocating the open access of scientific and scholarly knowledge. IRA Academico Research is a registered content provider under Open Access Initiative Protocol for Metadata Harvesting (OAl-PMH).

The journal is indexed \& included in WorldCat Discovery Service (USA), CrossRef Metadata Search (USA), WorldCat (USA), OCLC (USA), Open J-Gate (India), EZB (Germany) Scilit (Switzerland), Airiti (China), Bielefeld Academic Search Engine (BASE) of Bielefeld University, Germany, PKP Index of Simon Fraser University, Canada. 


\section{ABSTRACT}

Rural Revitalization cannot be carried out simply through industrialization that has been done by the traditional development. It needs the simultaneous development of primary, secondary and tertiary industries because the traditional development mode of rural tourism, which allows farmers to move away from villages and occupy good natural resources, has not been accepted. In the process of rural revitalization development, the village collective should play a major role in formulating standardized processes and methods, focusing on optimizing resources, excavating the unique culture of the countryside, and encouraging the villagers to participate actively. As an important link between villagers, tourists and the natural environment, rural leisure can promote villagers' return, retain tourists, and finally promote rural revitalization with the concept of ecological civilization, so as to realize the sustainable development of rural areas.

Keywords: Rural revitalization, rural leisure, villagers' participation, tourists' demand, experiencebased leisure activities

\section{Introduction}

In the Report of the 19th National Congress of the Communist Party of China, it is proposed to implement the Rural Revitalization Strategy and realize the "two-wheel drive" development of Rural Revitalization and new urbanization. In the future, there will be 300 million or 400 million people living in rural areas in China. Therefore, rural revitalization is very crucial.

The core of Rural Revitalization is the development of rural areas. The ultimate goal is to achieve the comprehensive revitalization of industry, culture, ecology, organization and talents [1]. The revitalization of rural industry, as the first of the five aspects of revitalization, has always been the focus of many scholars.

This paper analyzes the difficulties and problems of traditional tourism, and studies why traditional tourism mode is popular in the early stage of rural tourism, but there are many problems in the perspective of Rural Revitalization; At the same time, it explores the needs of consumers, studies the ways and management methods of villagers' participation in rural construction, and analyzes how rural leisure meets the needs of the new era. Taking Suining City as an example, it makes an empirical study on how to build rural leisure planning and design for the purpose of Rural Revitalization.

\section{The current situation and problems of traditional rural tourism from the perspective of "Rural Revitalization"}

\subsection{Problems in traditional rural tourism mode}

Rural tourism is a new growth point of rural economic development under the new normal, supporting the sustainable development of the rural economy, improving the environment of rural residents, improving the quality of residents, and increasing the income of residents [2]. But the ultimate part of the purpose often 
includes guiding the development of rural regional urbanization and tourism urbanization. At the same time, rural tourism encourages the intervention of enterprises and entrepreneurship, and the government only plays the role of regulator and coordinator.

This kind of development mode, the same as the tourism area, has the support of excellent environmental resources, characteristic resources and location conditions in the early stage, and then produces some successful tourist attractions. However, with the change of economic development, rural policy, residents' aesthetic and other factors, this traditional tourist resort is not very popular. On the one hand, with the change of tourism consumption, there are too many negative factors in the tourism mode of sightseeing. On the other hand, Rural tourism tourists do not want to take photos and watch something as they do in other scenic spots, so the tourism areas occupying the natural environment are often not visited by tourists [3].

\subsection{The influx of tourism capital leads to the industrialization of rural tourism}

In recent years, the tourism capital company has found the potential of rural tourism. At the same time, with the encouragement and support of the government, a large number of the rural and surrounding natural environment with the good environment have been transformed. But the purpose of capital is to seek profits. The way they usually take is to move the villagers away, leaving the vehicles far away from the core area of the tour, circling the mountains and rivers with a good environment, creating tourist areas, forming tourist links, and connecting only a number of attractions [4] through buses. This not only concentrates tourists in a small area, which greatly reduces the degree of leisure but also causes the waste of resources along the line. The construction of ancient towns and villages is even more uniform, and similar restaurants and retail businesses are introduced to create a pipeline mode. This kind of tourism development serves the capital of the tourism industry, neither for the tourists of rural tourism, nor for the villagers in the countryside, nor for the purpose of Rural Revitalization.

\subsection{Traditional rural tourism}

In terms of the development of the village itself, the development of the village led by the tourism industry has a series of benefits. However, in the process of construction, investors often pay more attention to the construction of health care facilities and other services for the tourism industry but ignore the construction and renewal of the village itself. Some villages will be attached to the health tourism town, so only a small part of the accommodation live catering function. Because the functional orientation and industrial characteristics of most health care towns are not clear, it is more difficult for the surrounding villages to form their own characteristics and positioning. Even if the village itself has unique resource characteristics, the additional industry is often the supporting industry of health care tourism town, and can not meet the market demand. At the same time, due to the low level of construction, the overall services and facilities are still very weak, which can not provide spiritual services for tourists.

In addition, the villagers' participation in the development process is low. Of course, this situation is also due to the villagers' low educational background and lack of enthusiasm to participate in the planning. More 
importantly, in the process of real estate development, the government and policymakers will not pay attention to the wishes of the villagers, and the deep culture of the village can not be protected. At the same time, in the process of construction, sustainable development is often ignored, short-term interests are often more concerned, and the protection of natural resources is insufficient, which will cause damage to the situation of the village itself.

\section{Rural leisure of consumers}

\subsection{The spiritual needs of tourists become the main driving force of travel}

The contemporary urban disease has brought about the physical and mental diseases of urban residents. The yearning for nature and nostalgia for the local promote the Utopia to help people escape from the city. Tourism products with "health + " elements, as well as tourism emphasizing the sense of social distance, including avoiding the world in space, staggered travel in time, small tourism groups in scale and customized travel, have become important reference factors for choosing tourism products [5].

With the increasing social pressure of young and middle-aged people, depression and other emotions seriously affect the mental health of modern people, the concept of "health and leisure" tourism has gradually come into people's vision. This concept is not only simply expanding the audience of the health and leisure industry from the simple elderly to the whole age group, but more importantly, the industrial development guided by the concept of health [6], More young and middle-aged people hope to get out of the city's living environment, into the slow pace of life in the countryside, and get spiritual and psychological relaxation.

\subsection{Analysis of tourists' demand for rural resources and facilities}

The traditional rural holiday tourists are mainly the elderly. These people have enough time to live in the village for a long time. It takes a quarter or even half a year, and most of them belong to the category of health care or leisure vacation. On the one hand, they need to provide a different life from the city in the countryside and have more opportunities to get close to the ecological nature; On the other hand, they hope to have friends as companions to enhance their feelings and have more semi-private space [7]; At the same time, they are often interested in traditional Chinese medicine, Buddhism and other traditional culture. In hot areas, the elderly usually go to high-altitude areas for summer with their children. They will live together in the countryside for 24 months.

There have been many studies on the needs of the elderly, but with the participation of young and middle-aged people in rural tourism, the evaluation of their needs by tourism developers is still the same as that of urban tourism, including better hotel and catering facilities, a number of recreational activities and multiple tourism routes. However, young and middle-aged people do not come to the countryside far away in order to get exactly the same experience as the suburbs.

In the process of investigation, we have issued a questionnaire in Jixiang District, Suining City, Sichuan 
Province, and obtained 48 valid questionnaires. Among them, 21 tourists are under 55 years old and 27 tourists are over 56 years old. Through the comparison, it is found that there is no significant difference between young and middle-aged ( 55 years old and below) and the elderly (56 years old and above) for rural leisure needs. Through the questionnaire survey and analysis, the excellent environment is still the primary demand of young and middle-aged people for leisure and health care in rural areas. Even young tourists especially explain that they do not want to build too many large facilities in the city in the village, which will damage the original style of the village. In other aspects, including suitable temperature, good air quality, good water quality, high vegetation coverage, similar diet and living habits, the three generations have higher requirements for these aspects, especially good water quality and good air quality.

In addition, young and middle-aged people need to be closer to home, which may be due to insufficient leisure time. Young and middle-aged people will have more demand for sports facilities; However, young and middleaged people hope to reduce socializing and make new friends during leisure time [7], and they hope to have more solitude.

\subsection{In the new era, people need more rural leisure than rural tourism}

\section{1) Rural leisure is not rural health}

The concept of health care tourism and health care town is becoming more and more popular. It will provide additional functions such as medical recuperation, rehabilitation and mental adjustment for the tourism town, which is also a slow way of vacation. However, the health care industry has certain limitations for the village itself, the village infrastructure is weak, especially in the medical aspect, large or specialized hospitals are not suitable for supporting in the countryside. In addition, most tourists want to experience different rhythms of life when they travel in rural areas, rather than to get better medical conditions than in cities. Tourists of all ages think that the medical conditions in rural areas are worse than those in urban areas. At the same time, $87 \%$ of them think that medical conditions will not be the reason for their choice of rural areas. Some tourists also propose that leisure villages need basic medical conditions.

Tourists who choose rural leisure will think that a good natural environment can improve their health to a great extent, rather than seeing a doctor; A small number of elderly people also have their own views and needs on traditional Chinese medicine, such as the demand for Angelica dahurica in Jixiang District in the process of investigation.

\section{2) New demands of rural leisure benchmarking tourists}

Traditional tourism needs distinctive resources. People go to new places to see things they can't see at ordinary times. However, with the development of the Internet and the popularity of tourism, this unique resource advantage does not exist. The advantage of the rural natural environment is not only viewing but also providing a place to live in nature. 
Traditional tourism has fixed routes and consumption points. In this oppressive mode, even when enjoying the scenery, tourists can not feel relaxed and leisure. Instead, they have to work hard to complete one task after another. In the process of rural leisure, people want to be able to feel the countryside in many aspects and be able to sit freely in the beautiful scenery. Tourists prefer to drive through the winding country road to the residence in the countryside. There are viewing platforms on the small scenic spots along the road to take photos and enjoy the scenery. Therefore, rural leisure is to create a relaxed and natural environment, so that tourists do not exclude consumption, meals and accommodation in this environment.

\section{Rural leisure helps to complete "Rural Revitalization"}

\subsection{Rural Revitalization is the goal of rural leisure development}

Farmland and village are not only the spatial basis of rural revitalization but also the target carrier of Rural Revitalization. When doing rural leisure development, we should focus on the protection and utilization of farmland and the protection of local residents' living space [2]. All the elements in the countryside are sticky and a community. General secretary Xi Jinping stressed that "rural replacement and resources have three functions and attributes of" production, life and ecology ", which indicates that the rural environment and resources are characterized by" structural sticky ". The" Sanshui Tian Tian Hu Cao "and the" Sansheng co-ordination "proposed by President Xi are not separable, and only [8] can be developed comprehensively. On the one hand, as the basis of rural revitalization, rural leisure needs the integration of primary, secondary and tertiary industries, with farmers as the main body and the combination of agriculture, culture and tourism to ensure the revitalization and activation of rural areas; On the other hand, rural leisure focuses on the real needs of consumers and provides an experience that does not exist in the city.

In the planning of rural leisure, we should avoid the design of large tourist areas and ring roads, which will only turn away leisure consumers. Combined with the surrounding mountains, rivers, forests, fields, lakes and grasses, the village is a large tourism area. There is no boundary, no tour line, and no "ticket" required. People can freely enter nature [3]. Good natural environment is not the financing chip of the tourism industry and real estate industry, but the place where villagers live for generations. This model needs the rural collective to play a greater role in preventing excessive capital from entering the rural areas. We should pay attention to the longterm effect and take the revitalization of rural areas as the ultimate goal. The village collective should ensure that the basic agricultural production always exists, the traditional village still exists, and the villagers also live, so that the function of "three living" can play a role. Leaving only the service industry is a way to forget the goal. This is only in the development of tourist areas, not villages. Only with the existence and development of agriculture and industry can the primary, secondary and tertiary industries be integrated and the countryside is revitalized.

\subsection{Experiential rural leisure promotes rural activation and keeps tourists}

\section{1) Villagers are encouraged to participate in rural leisure construction}

The process of villagers transforming the rural environment and style for the leisure industry is a very good 
process of village activation. Residents with technology or capital can participate in the process of rural transformation. Based on the experience of Taomi village activation in Taiwan, we can hire carpenters to build public buildings in the village, and villagers can build them through discussion and research; Some villagers have already mastered the means of online broadcast, which can help to publicize the rural leisure brand, agricultural and sideline products and characteristic scenic spots. With the increase of rural fame, it can solve the problem of hollowing out of the countryside to a certain extent, attract some young people to return to the countryside and participate in the rural construction. It can also naturally drive the villagers' willingness to participate in rural construction and enhance the connection between the countryside and the villagers [9]. At the same time, with the active participation of villagers, rural food, festival tradition, handicrafts and other cultural resources can also be in-depth excavation and dissemination, culture has become a new development point of rural leisure.

\section{2) Rural leisure establishes the link between tourists and rural areas}

The emotional connection between tourists and the countryside stems from the experience of rural life. Tourists not only need to watch the countryside, but also can experience the countryside. Tourists are very willing to participate in the work or transformation of the village in the process of leisure, and people will take the initiative to experience different lives. Different from the reinforced concrete environment of the city, everything around belongs to the city, and people can't change the surrounding environment. In the countryside, from building a shed to planting flowers, or drawing the first and only publicity wall, the experience of personally changing the surrounding environment is often loved by the public. Through this kind of activity experience, the public tourists will have feelings for the village in the process of experience, so they come to the same village many times for leisure. This model is also suitable for long-term vacation and leisure villages. For example, tourists in summer villages often live in the villages for 1 to 3 months. In a longer period, tourists can have a more comprehensive and in-depth understanding of the changes in the villages. Through long-term participation in the personally transformed villages, tourists will have a strong emotional resonance with the villages, and tourists will be more easily fixed.

\subsection{Encourage village collective to lead rural leisure}

In the development of rural leisure industry, villagers will spontaneously provide related services, especially catering and accommodation. In the survey, we found that even in the villages where rural leisure has just started, a few villagers have opened rural hotels, but this spontaneous behavior often does not get the attention and support of village managers.

On the one hand, villagers are eager to increase their income and develop the service industry; on the other hand, it is difficult to reach a consensus between villagers and village managers. Village managers usually need to build new houses on the construction land in order to build snack street and Farmhouse Hotel. However, tourists often want to experience the ecological natural environment and village. Some village managers put forward to rent uninhabited village houses, through decoration and reconstruction, to build a tourist favorite experience 
hotel. However, villagers usually prefer to idle rather than rent houses. In this case, we should help village managers to make a complete plan of renting village house or using idle homestead, set fixed rent standards and implement policies, and promote the construction of rural experience hotel.

\section{Conclusions}

Rural leisure should replace the traditional rural tourism, not the idea of tourism area and tourism line, but closely combined with ecological civilization and the overall planning of rural landscape, forest, lake and grass, reflecting the primary position of people, including the essential needs of tourists and villagers as life body, so as to build rural leisure while completing Rural Revitalization [10].

In terms of policy, the government needs to change its mind to prevent tourism capital from entering the countryside in disorder and ensure the foundation of Rural Revitalization. In terms of management, village managers, as grass-roots management units, should set up special systems and methods to lead the construction of rural leisure; At the planning level, priority must be given to maintaining the overall pattern of rural and surrounding environment, while ensuring the integration of primary, secondary and tertiary industries in rural areas, and the layout of leisure service industry should be based on agriculture and industry; On the design level, it needs to be based on the living space of tourists, so that tourists can slowly experience the countryside, feel the life different from the city, and give tourists and villagers more contact opportunities to promote the rural activation; On the operational level, we should encourage villagers to participate in rural construction, guide villagers to return, strengthen the emotional connection between villagers and villages, increase villagers' income and realize rural revitalization.

\section{References}

[1]. Liu Yansui. Urban rural integration and Rural Revitalization in the new era of China [J]. Acta Geographica Sinica, 2018, 73 (4).

[2]. Tao Tao. Research on rural tourism-oriented village planning strategy [D]. Zhejiang University, 2014

[3]. Wen Tiejun. Rural Revitalization under the strategy of ecological civilization.

[4]. Lu Lin, Ren Yisheng, Zhu Daocai, et al. Research framework and Prospect of rural tourism guiding rural revitalization.

[5]. Bian Suping. Research on rural cultural protection and beautiful rural construction under the background of new urbanization [J]. Rural agriculture farmers B, 2020, 000 (005): 11-12.

[6]. Fan Yinan, Chen Lijuan. Research on the development of health care town under the background of aging population [J]. Technical economy and management research, 2020 (10).

[7]. He Mang. Research on the construction of health care tourism characteristic town based on demand orientation [J]. Journal of Beijing Union University (Humanities and Social Sciences), 2017 (2).

[8]. Jin Yuanyuan, Wang Shufang. Research on the integration development of ecotourism industry and health industry under the background of Rural Revitalization Strategy [J]. Ecological economy, 2020, V. 36; No.349(01):142-147. 
[9]. Zhang Zhiqiang. Research on the renewal of rural community under the mode of "community construction". Xiamen University.

[10]. Wen Tiejun. New kinetic energy of domestic big cycle strategy in rural areas [J]. Romantic generation, 2020, No. 866 (27): 36-37. 